\title{
The Study of Regional Economic Development and Talent Ecosystem
}

\author{
Aihong Li \\ Shandong Yingcai University, Ji'nan, 250014, China
}

\begin{abstract}
Keywords: Regional economy development. Talent ecosystem. Study. Harmonious development
\end{abstract}
\begin{abstract}
Under the background which China`s economy enjoys fast and sound development, it also face the uneven regional economy development, the gap between all the region is also getting larger and larger. While in order to control this trend, we must be talent-oriented, the most important resource is the talent, human resource is the driven force behind the regional economy development, only by bringing human resource into full play, can we better play the role as the transfer station in the eastern coastal areas, and further develop the middle regional economy, and better realize the goal of develop the West region development, promote the economy development of different regions. For that, it is of significant meaning to explore the regional economy development and human resource ecological system.
\end{abstract}

\section{The analysis of the current situation of the regional economy development}

Currently, China`s economy universal problem in the transition period is the uneven development of the regional economy. Due to the fact that China remains a developing country. So the nature of the nation require a healthy, orderly, coordinated development of different region, especially the stark divide and unlimited gap between different regions are absolutely prohibited, let alone the polarization, once this is occurred, it will undoubtedly effect the economy development, political stable and nation unity of our country, this actually a betray to the inner requirement and attribute of socialism, this is counterproductive to the development of socialism country. Although the economy in China has enjoyed continuos and fast development, but due to the difference in the subjective and objective conditions and historic and realistic reason, the uneven development in different region is very prominent, mainly manifested as:

First, although there has formed Peral River Delta, Yellow River Delta and economic belt surrounding the bohai sea and many other economy zone in China, but this growing polars remain powerless in regard of radiation effect and range.

Second is the uneven economy development in the three major economy zone. Ever since the implementation of reform and opening up policy, the economy development level in the western and middle part of China has exceeded some of the provinces in the east coastal line, but judging from the overall economy strength, the proportion of the east coastal region`s GDP continuously climbing high remain a fact, the economy development quality and speed remain the descending situation from the east to the west, besides the gap between three major region is still on the rise.

The third is that the difference in the different places within each region has lead to the different industry elements and structure survival rate, the economy difference inside these regions and the difference between the three major regions are particularly significant, it is an important part of the integrated regional economy development difference.

The forth is the gap between the north part and south part in east and middle region constantly increases, according to the research of the relevant scholars and experts, the economy development in the south part in both east and middle region is very rapid, while the north part is relatively slow due to the geography condition, this situation brought some new uneven factors to the regional development in China.

The reasons for this huge gap are various, but the uneven development of the capital market is an important reason. By comparing the capital market in the four major economy zones, we can find that there are obvious uneven situation in the capital market development in east, middle, north-east, west region`s capital market. 


\section{Regional economy development`s develop function for talent ecosystem}

\section{The configuration function of the regional economy development for talent ecosystem}

The regional economy development's configuration function to the talent ecosystem is an essential link in making sure the graduates can enter into the working state and get used to all the mission and work assigned by the company and truly serve the society as a talent. On one hand, the regional economy development's configuration function to the talent ecosystem must be in accordance with the talent resource cultivation capability, thus to make sure the graduates can enter the practical stage continuously. So the corporation should adhere to the basic principal of combining the government macro-regulation and market allocation, constantly strengthen the allocation function of the market to human resource, thus to free the human resource flowing channel. On the other hand, the corporation regional economy development must have the reallocation function, because it takes reallocation to let all the different talent to acquire different skills through constant learning and practice. This could better play its role and realize its values. At last, the regional economy development must build a comprehensive information feedback system in the process of talent ecosystem allocation, adjust the training structure of human resources by the hand of market, and by doing this, we can better adjust to the changing society, constantly transform and upgrade the economy structure.

\section{The using function of the regional economy development to talent ecosystem.}

The final goal of the regional economy development's allocation to the talent ecosystem is properly using the talent, if we deploy and use the talent properly, then higher input to the human resource will create higher yield. On the contrary, if we did not use it properly, then it would create waste for the human resource. Generally speaking, the regional economy development`s using function to he talent ecosystem should follow the following principals:

The first is the structure optimizing principal. Adhere to the best structure inside the talent group, let the deployment and their relationship tend to be in the best state. The second is the classification principal. The basic principal for realizing the rational deployment of the human resource is the multi-dimension and deep classification, such as we can divide according to the personality character,knowledge structure, talent type, thinking type and personality difference. The third is the dynamic principal. According to the talent or position requirements changes to conduct rational deployment of the talent, thus to further promote the rational flow of the human resource. The forth is energy level corresponding principal. Place the talent in the right place which is in accordance with their energy level, thus to bring the human resource into full play. The fifth is incentive, continuous explore the rational needs of the talent, make the talent have higher goal and pursue, constantly encourage and activate their creativity and activity.

\section{Regional economy development's cultivation function to the talent ecosystem}

Regional economy development's cultivation function to the talent ecosystem is mainly realized by self-cultivation and organization cultivation. On one hand, simulate the talent to do self-cultivation by using the factors in the environment. The self-cultivation is based on the active behavior, it emphasize more on the talents ' needs to develop themselves, so this needs actually come from the talent themselves, they usually have very strong develop desire and needs, so this kind of people are more likely to become a useful people. On the other hand, conduct organized cultivation to the talent by using regional economy development`s organization function. The organization cultivation includes constant training and education to the members inside the organization, build all kinds of incentive systems inside the organization, conduct rational deployment and using to the personnel, provide fair and justice opportunity etc. So the organization cultivation emphasize on the external factors, but its nature is by personnel system`s effective implementation and rational setting to take the biggest advantage of the talents inside the organization. 


\section{Human resource`s space distribution`s effect to the regional economy development}

\section{Human resource`s diffusion effect to the regional economy development}

One side of the agglomeration effect of the human resource, is when the agglomeration effect of human resource grow into a certain scale, it will inevitably create a relatively strong attraction to other elements and economy activities, so improve the investment environment of the flow-in region, thus to generate economy and scale economy, by doing this, it would be very conductive to accelerate the regional economy`s rapid development and expansion. On the other hand, the agglomeration effect of the human resource also made the talent team constantly expand in this region, especially the continuous build-up of the professional talent which is in accordance with the regional economy development, to some extent, this professional human resource have greatly promoted the development of the regional economy by increase the productivity survive rate and technology reform innovation.

\section{The effect of the human resource`s aggregation effect to regional economy development}

Under the function of the human resource diffusion system, most of the talents will continuously spread to the lagging regions, this is very beneficial to the improve the investment environment of the lagging regions, and create a new-type regional relationship in this regional economy coordinated development, this promote the continuous development of the economy in this region virtually. Among that, the diffusion effect of the human resource will be effected by the following elements: all the talent will try to find better development opportunity. Because of the high living cost and the fierce survive competition and rare good opportunity, in the talent agglomeration area, most people will turn to other region to seek better chance to realize its self-value. The second is reduce the negative externality of the agglomeration. The diffusion effect of the talent is conductive to reduce the negative externality of the agglomeration. The third is the common function of the government economy and social development policy, in order to solve the pressure brought by the resource, environment and population,the government will encourage and arrange the people in the gathering area spread to the other region, on the other word, it is the macro-control function, the forth is the function of the economy activity location direction. Because the material needed in part of the economy activities will attract the correspondent human resource to this region.

\section{The harmonious development of regional economy development and talent ecosystem}

\section{The macro-regulation of the government}

All the functional department, every level of the government and non-governmental sector etc make up the government regulation system together, its regulation measure includes finance,taxation, fiscal, law and regulations. Such as the government directly support the human resource R\&D work by fiscal transfer payment, direct loans, subsidies, civil construction and taxation arrangement and some other measures, it can also promote the talent ecosystem in indirect way like financial loans; or standardize the human resource market system by comprehensive rules and norms, thus to make sure the effective assurance for the talent individual; in the end, guide the talent capital's structure investment and plan, in the end, the government can guide the human capital`s structure investment and plan by differentiation human resource development policy.

\section{The macro-regulation of the market}

Although the human capital returns are different in different type or level, let alone there might be some distance in the same human capital in different industry and regional space, however, under the driven of interest mechanism, the market entities have different supply degree and needs in different levels and types, and as regional economy development has reached the balance between the demand and supply of different types of human capital within the region. In another words, the human resource space structure will go forward along with the regional economy`s development, thus it can reach the ultimate goal of controlling the human resource space structure and regional economy development by market mechanism system`s regulation function to the supply and demand situation of different human resource. 


\section{Mixture of the both regulation measure}

The mixed regulation methods means to interfere the regional economy effectively by the "visible hand" which is government, thus to simulate the increase of the total needs, and push the economy returns to the sufficient employment, when the economy is close to or has already been close to the sufficient employment, we can give the "invisible hand" more freedom. So under the measure of mixed regulation, the regional economy development and talent ecosystem can be mutual complementary, mutual promote and enjoy continuous development. On one hand, the promotion and optimizing of the talent resource has provided solid human resource and structure support, in this mutual promotion and mutual effect process, human resource and regional economy has formed a very good interactive cycle, it can balance the regional development, and realize the goal of coordinated development and continuous pushing, it can also bring an individual's value into full play by the best space configuration. On the other hand, the development of the regional economy also increases the supply level and capability of an individual's human capital, which virtually pushes the promotion and improvement of the talent ecosystem, and it also makes the human resource`s industry configuration more rational and perfect.

\section{Acknowledgments}

This paper is Shandong Yingcai college key subject+Yellow river Delta ecology economy zone talent ecosystem; subject code: 13YCDRW08; subject fund: Shandong education science "the twelfth five-year plan” project (key ) subject+ Shandong regional economy industry structure adjustment and vocational education development mode transformation vertical study; subject number: 2013GZ051

\section{Reference}

[1] Xin Wang, Qi Hong the strong emerge of three main urban cycle[N] People's Daily Overseas Edition,2011

[2] Wang Ying, Xu Yang It Is Much Safer to Have a Golden Job: On the Popularity of Civil Service Examination Among the College Students[N]Economic Reference Press,2009

[3] Zhang Xiangqian Talent strategy and Chinese economy study[M] Beijing: Central Compilation and Translation Press, 2010

[4] Jing Tihua 2004-2005China regional economy development report[M]Beijing: Social Sciences Academic Press 2005

[5] Wang Qingdong China Talent Security is Not Positive[N] Global Times,2003

[6] Liao Quanwen the Theory and Practice of Chinese Labor Market[M] Shandong People`s Press,2010 